\title{
Drama as a community engagement strategy for malaria in
}

\section{rural Cambodia [version 1; peer review: 1 approved, 2}

\section{approved with reservations]}

\author{
Renly Lim(iD1,2, Rupam Tripura (iD1,3, Thomas J Peto(iD1,4, Ma Sareth1, Nou Sanann1, \\ Chan Davoeung ${ }^{5}$, Chea Nguon 6 , Phaik Yeong Cheah (iD) 1,4,7
} \footnotetext{
Adelaide, Australia

${ }^{3}$ Faculty of Medicine, University of Amsterdam, Amsterdam, The Netherlands

${ }^{4}$ Nuffield Department of Clinical Medicine, University of Oxford, Oxford, UK

${ }^{5}$ Provincial Health Department, Battambang, Cambodia

${ }^{6}$ National Center for Parasitology, Entomology and Malaria Control, Phnom Penh, Cambodia

${ }^{7}$ The Ethox Centre, University of Oxford, Oxford, UK
}

${ }^{1}$ Mahidol Oxford Tropical Medicine Research Unit, Faculty of Tropical Medicine, Mahidol University, Bangkok, Thailand

${ }^{2}$ Quality Use of Medicines and Pharmacy Research Centre, School of Pharmacy and Medical Sciences, University of South Australia,

\section{V1 First published: 29 Sep 2017, 2:95 \\ https://doi.org/10.12688/wellcomeopenres.12594.1}

Latest published: 16 May 2018, 2:95

https://doi.org/10.12688/wellcomeopenres.12594.2

\begin{abstract}
Background: Countries in Southeast Asia are working to eliminate multidrug-resistant falciparum malaria, a major cause of mortality in tropical regions. Malaria is declining but transmission persists in many rural areas and among forest workers and isolated populations. In these remote communities, conventional health services and education are limited. Mobilising and educating these populations require new approaches as many people are illiterate and do not attend village meetings. This article describes a qualitative study to assess the feasibility of a drama project as a community engagement strategy.

Methods: A drama project was conducted in twenty villages in Cambodia with three key messages: to use insecticide-treated bednets and repellents, to get early diagnosis and treatment, and to learn about risks of forest-acquired malaria. Qualitative interviews were conducted with the drama team members, village malaria workers, local health staffs and villagers, to explore the feasibility of using drama to engage the community and the associated challenges. Results: 29 people were interviewed, which included 18 semistructured interviews and one focus group discussion. Analysis of the interviews resulted in development of the following seven themes: i) exposure to malaria and engagement activities, ii) readiness and barriers to participation, iii) understanding and learning about malaria using drama, iv) entertainment value and engagement method preferences, v) challenges to community engagement, vi) future
\end{abstract}

Open Peer Review

\begin{tabular}{|c|c|c|c|}
\hline \multicolumn{4}{|c|}{ Approval Status $?$} \\
\hline & 1 & 2 & 3 \\
\hline \multirow{4}{*}{$\begin{array}{l}\text { version } 2 \\
\text { (revision) } \\
16 \text { May } 2018\end{array}$} & & & \\
\hline & $?$ & & $\checkmark$ \\
\hline & view & & view \\
\hline & $\|$ & & 1 \\
\hline version 1 & $?$ & $\checkmark$ & $?$ \\
\hline 29 Sep 2017 & view & view & view \\
\hline
\end{tabular}

1. Gillian F. Black ID, Sustainable Livelihoods Foundation, Cape Town, South Africa

2. Mary Chambers ID, Oxford University Clinical Research Unit (OUCRU), Ho Chi Minh City, Vietnam

3. Alun Davies (D), Kenya Medical Research Institute-Wellcome Trust Research Programme, Kilifi, Kenya University of Oxford, Oxford, UK Any reports and responses or comments on the 
participation and vii) sustainability. The event saw a very positive response, with an encouraging average participation rate of $66 \%$. The article can be found at the end of the article. project faced several challenges including logistic problems, rescheduling due to raining season, and time- and budget-constraints. Conclusions: Our evaluation demonstrated that the drama project was feasible in promoting awareness and understanding of malaria prevention and control. Audience members perceived drama as entertaining and as the preferred choice of engagement activity. Participatory drama could be considered as part of the community engagement for malaria elimination.

Keywords

malaria, elimination, public engagement, community engagement, drama, Cambodia, evaluation

This article is included in the Mahidol Oxford

gateway.

\section{Corresponding author: Renly Lim (renly.lim@outlook.com)}

Author roles: Lim R: Data Curation, Formal Analysis, Investigation, Methodology, Software, Writing - Original Draft Preparation, Writing - Review \& Editing; Tripura R: Conceptualization, Data Curation, Investigation, Methodology, Project Administration, Supervision; J Peto T: Conceptualization, Data Curation, Investigation, Methodology, Project Administration, Supervision; Sareth M: Investigation, Methodology, Project Administration; Sanann N: Investigation, Methodology, Project Administration; Davoeung C: Project Administration, Supervision; Nguon C: Project Administration, Supervision; Cheah PY: Conceptualization, Data Curation, Funding Acquisition, Project Administration, Supervision, Writing - Review \& Editing

Competing interests: The authors declare that they have no competing interests.

Grant information: This work was supported by the Wellcome Trust [096527 and 106698]. The funders had no role in study design, data collection and analysis, decision to publish, or preparation of the manuscript.

Copyright: ( 2017 Lim R et al. This is an open access article distributed under the terms of the Creative Commons Attribution License, which permits unrestricted use, distribution, and reproduction in any medium, provided the original work is properly cited.

How to cite this article: Lim R, Tripura R, J Peto T et al. Drama as a community engagement strategy for malaria in rural Cambodia [version 1; peer review: 1 approved, 2 approved with reservations] Wellcome Open Research 2017, 2:95 https://doi.org/10.12688/wellcomeopenres.12594.1

First published: 29 Sep 2017, 2:95 https://doi.org/10.12688/wellcomeopenres.12594.1 


\section{Introduction}

Countries in South East Asia are working towards the elimination of Plasmodium falciparum, a major cause of mortality in tropical regions ${ }^{1,2}$. In Cambodia, malaria prevention and control programmes have made significant progress and malaria cases have declined substantially ${ }^{3}$. Unfortunately, emergent artemisininresistant $P$. falciparum threatens the recent gains ${ }^{4-7}$.

In January 2016, the Cambodian National Centre for Parasitology, Entomology and Malaria Control (CNM) announced the Malaria Elimination Action Framework (MEAF) 2016-2020, which aims to eliminate $P$. falciparum by 2020 and P.vivax by $2025^{8}$. The elimination efforts are underpinned by CNM's village malaria worker (VMW) programme, where the VMWs provide early, free diagnosis and treatment in settlements with the highest prevalence ${ }^{9}$. Achieving elimination is complicated by several factors. For example, in areas of low and falling transmission, those at highest risk of infection, forest goers and migrant groups, are the hardest to reach with health services and health education ${ }^{10,11}$. Moreover, the success of the VMW programme is predicated on the sustained motivation of isolated VMWs and local communities making use of the services they offer.

In rural communities affected by malaria, awareness and understanding of the disease and the VMW programme is indispensable to support elimination efforts. Such communities however often record lower literacy rates compared to urban areas: 77 percent compared to 93 percent in the 2014 census $^{12}$. Using printed media such as leaflets and posters to raise malaria awareness, may therefore be less successful in these areas. In developing countries, folk media such as folk songs, dramas, puppet shows and dance have been used as community engagement strategies for health education and to encourage research participation ${ }^{13-15}$. Khmer dramas which use comedy and music to tell stories with local references and language that resonates with villagers are popular in rural communities. In light of the need to convey messages about malaria and the VMW programme in a comprehensible and appropriate fashion, traditional Cambodian drama was used as a means to supplement existing text-based messaging on malaria and other efforts rolled out by the local authorities and education system. The Village Drama Against Malaria (VDAM) was a pilot project that sought to encourage people to prevent mosquito bites by using insecticide-treated nets and repellents, get early diagnosis and treatment from the VMWs, and to raise awareness about the risk of malaria in local forests.

This paper describes a qualitative study to:

i) assess the feasibility of the VDAM project as a community engagement strategy,

ii) use drama and related workshops to convey the three key messages of the project (to use insecticide-treated nets and repellents, to get early diagnosis and treatment, and to raise awareness about the risk of malaria in local forests); and

iii) describe the challenges faced by the VDAM team, local team members and villagers.

\section{Methods}

\section{Setting}

The Village Drama Against Malaria (VDAM) project $^{16}$ was a joint initiative of the Battambang Provincial Health Department and the Mahidol-Oxford Tropical Medicine Research Unit (MORU), funded by the Wellcome Trust. MORU has a long-standing collaboration with the Battambang Provincial Health Department.

The project was conducted in 20 of the 49 remote villages in the Samlout District of Battambang Province, which is located in the western Cambodia near the Thailand border (Figure 1). These 20

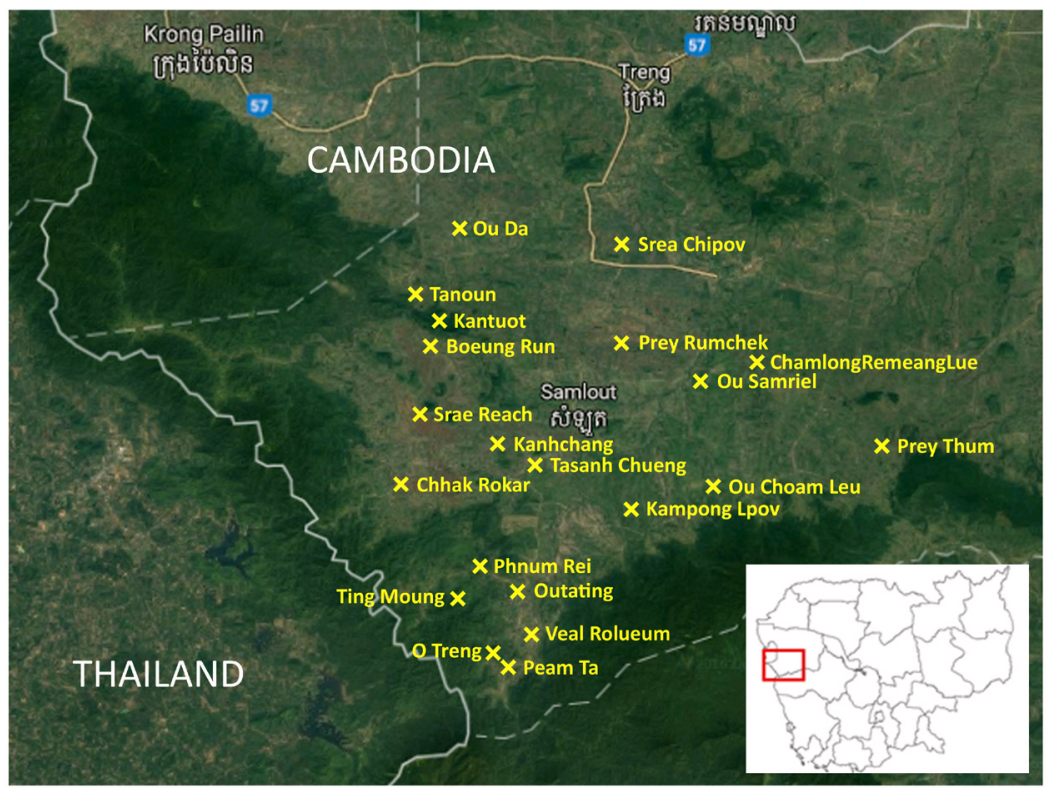

Figure 1. Location of the $\mathbf{2 0}$ drama villages in the Samlout district of Battambang province. 
villages were selected by the provincial health department based on their high P. falciparum incidence from VMW records in 2014, and a proven prevalence of subclinical malaria infections from crosssectional surveys in early 2015.

Village populations ranged from approximately 150 to 3000 residents with an average of 800 (Table 1). Villagers are generally poor and most families are involved in small-scale agriculture. The villages typically have only basic infrastructure: poor access to potable water, sanitation and irrigation systems, limited electricity supplies, minimal post-primary education, and poor availability of health services. The villagers consist of majority ethnic Khmer with some ethnic minorities, chiefly the Por group, living in some villages close to the forests along the Thai border.

\section{The VDAM community engagement project}

The VDAM project combined Cambodian drama, art, music workshops and village concerts and competitions to provide health education in a fun and engaging way. Cambodian drama uses caricatures in a funny and irreverent manner and the VDAM productions did so to weave together stories and health education. The project mixed art and drama with modern technologies, such as using drones to film the villages, and social media (Facebook and YouTube) to share photos and videos across the province. The 'Village Drama Against Malaria' Facebook page was updated regularly after every drama performance depicting highlights of the 3-day events.

\section{Planning}

The VDAM team first introduced the project to and sought approval and support from the national authorities. Meetings were held in the target communities with village leaders, key opinion leaders identified by staff of the provincial health department and other prominent members to deliberate on the proposed project.

Professional drama performers were recruited in Battambang province. A series of workshops were organised to train the team on the malaria messages to incorporate into the drama performance. The final main script, storyline and key messages were approved by the provincial health authorities.

Table 1. Audience numbers, total population and percentage attendance in each of the twenty villages.

\begin{tabular}{|c|c|c|c|c|}
\hline Number & Village & $\begin{array}{l}\text { Audience } \\
\text { numbers }\end{array}$ & Population & $\begin{array}{l}\text { Percentage } \\
\text { attendance }\end{array}$ \\
\hline 1 & Outreng + Peamta & 350 & 522 & 67.0 \\
\hline 2 & Vealroleum & 250 & 291 & 85.9 \\
\hline 3 & Ting Moung & 70 & 153 & 45.8 \\
\hline 4 & Phnom Rei & 500 & 614 & 81.4 \\
\hline 5 & Ouda & 650 & 1012 & 64.2 \\
\hline 6 & Srea Chipov & 550 & 1537 & $35.8^{\#}$ \\
\hline 7 & ChamlongRemeangLue & 450 & 1450 & $31.0^{\#}$ \\
\hline 8 & Tasanh Chueng & 350 & 949 & 36.9 \\
\hline 9 & Boeung Run & 600 & 814 & 73.7 \\
\hline 10 & Prey Thum/MaiKo & 350 & 313 & $111.8^{*}$ \\
\hline 11 & Ou Choam Leu & 350 & 456 & 76.8 \\
\hline 12 & KampongLpov & 450 & 298 & $151.0^{*}$ \\
\hline 13 & Chhak Rokar & 500 & 1781 & $28.1^{\#}$ \\
\hline 14 & Srae Reach & 450 & 562 & 80.1 \\
\hline 15 & Outating & 150 & 164 & 91.5 \\
\hline 16 & Kanhchang & 450 & 649 & 69.3 \\
\hline 17 & Prey Rumchek & 600 & 3361 & $17.9^{\#}$ \\
\hline 18 & Ou Samriel & 550 & 793 & 69.4 \\
\hline 19 & Tanoun & 450 & 822 & 54.7 \\
\hline 20 & Kantuot & 550 & 1020 & 53.9 \\
\hline \multicolumn{5}{|c|}{$\begin{array}{l}\text { Key: } \\
\text { t: These villages are very large in size, making it difficult for villagers to attend the } \\
\text { drama event. The majority of villagers commute on foot. }\end{array}$} \\
\hline \multicolumn{5}{|c|}{$\begin{array}{l}\text { *: Percentage attendance exceeded } 100 \% \text { because participants came from nearby } \\
\text { villages to attend the drama event. }\end{array}$} \\
\hline
\end{tabular}


In each village, the team and village leaders met with the local community members and VMWs to explain the purpose of the project and to introduce the activities involved. Key opinion leaders in each village played an active role throughout the project development and progress.

\section{Drama workshops and performances}

The project, which took place from June until September 2016, comprised a series of three-day workshops with the drama group travelling from one village to another every third day. During the workshops, villagers shared their talents and local stories which were integrated as part of the drama performance. School children were invited to participate to sing songs about malaria in Khmer and create drawings with the malaria theme. Teenagers and young people were invited to participate in the drama. On the third evening, the activities included singing competitions, songs and a quiz on malaria, followed by a 45-minute drama performance by both locals and professional drama team members. These events took place in the village square, usually near a school or temple, starting about $6 \mathrm{pm}$ and ending at $10 \mathrm{pm}$ or $11 \mathrm{pm}$.

\section{Data collection}

Our sampling method was purposive and limited by practicalities. In July 2016, 18 semi-structured interviews and one focus group discussion were conducted. The semi-structured interviews included six villagers who attended the drama performance, five professional actors, two VDAM organisers, two provincial health department staff, one VMW, one village leader and one local health staff. One focus group discussion took place, which involved eleven youths aged between 14 and 16 who participated in the performance.

Interviews were conducted by two interviewers (RL and PYC) in English and Khmer with the help of a Khmer social scientist (NS). All interviews, including the focus group discussion, were recorded with permission of the interviewees. In addition, data were obtained from field notes based on observations and informal conversations.

Interview guides explored the following areas:

i) personal history and experiences with malaria and community engagement,

ii) perceptions of malaria prevention and treatment,

iii) understanding of malaria messages conveyed via drama;

iv) opinions on the community engagement method,

v) challenges to organizing the community engagement or attending the event and

vi) feedback and suggestions on community engagement.

Audio recordings of interviews were transcribed and translated where necessary into English by professional translators. Two authors (RL and PYC) performed manual line-by-line coding of all interview transcripts in Microsoft Word. Using thematic analysis, the content of the codes were used to develop the themes that are presented below and to explore patterns of these themes across the transcripts/data sources.

\section{Ethical statement}

The study was approved by the Oxford Tropical Research Ethics Committee (OXTREC; 1015-13), National Ethics Committee for Health Research Cambodia ( $18^{\text {th }}$ Feb 2016 NECHR 0051), and registered on clinicaltrials.gov (NCT01872702). Verbal informed consent was obtained from all participants prior to commencing the interviews and questionnaires. Verbal instead of written consent was obtained due to cultural reasons, and due to the low literacy level in the remote villages. The consent process was recorded using an audio recorder. Verbal consent for this study was approved by OXTREC in accordance with their guidelines on consent (https://www.admin.ox.ac.uk/curec/ resources/informed-consent/), as well as the local ethics committee. Approvals for the VDAM project, use of social media as well as filming and photography for all public events were obtained from the national and provincial authorities prior to the start of the project.

\section{Results}

Analysis of the data resulted in the following seven themes:

i) exposure to malaria and engagement activities,

ii) readiness and barriers to participation,

iii) understanding and learning about malaria using drama,

iv) entertainment value and engagement method preferences,

v) challenges to community engagement,

vi) future participation; and

vii) sustainability.

\section{Exposure to malaria and engagement activities}

Interviews with local villagers revealed that either they themselves had contracted malaria, or know people who had contracted malaria. Villagers who had contracted malaria said that they suffered from its symptoms and economic complications, including inability to work and loss of income. Villagers who had personal experiences with malaria recognized its seriousness, and would seek diagnosis and treatment from VMWs. Some villagers shared stories of immigrants and outsiders who died after contracting malaria in the villages.

"Since one of the actors from this group died, then never has any other group which does the drama performance come to perform at this village any more."

(Village leader)

Community engagement activities were few and far between, and involved only showing videos and films, without active participation from the community. Staff from the local health authority felt that the existing health education methods, through healthcare centres, hospitals, advertisement (e.g. banners), media (e.g. television) and local service providers were limited and not comprehensive. Others commended the unique approach of the current participatory drama project. 


\section{Readiness and barriers to participation}

Many villagers expressed their readiness to participate in the drama activities, as reflected by an encouraging average participation rate of $66 \%$ (range $18 \%$ to $100 \%$ ) (Table 1). The number of attendees was between 70 and 650, with an average of 430 people. Many young people and children volunteered to participate during the workshops to showcase their performance talents. For many, this was the first time they received drama training and had the opportunity to perform in public.

Villagers said that their motivation to join the workshops stemmed from a desire to learn and understand more about malaria, and they hoped to get more information to eliminate malaria in their villages. Village leaders were interested in the project because they wanted to know more about the on-going projects conducted by MORU and the provincial health department.

The lack of transportation meant villagers often commuted on foot, making accessibility to the performance location potentially difficult. A few villages such as Srea Chipov and Prey Rumchek are very large in size. Villagers may not be able to attend the drama due to the distance, which potentially explains the lower coverage in these villages (Table 1). Interviews with participants in other villages, however, showed that they had no problem walking to the pagodas or schools where the drama performances were conducted. The villagers who were interviewed said that they went with their entire families. They were happy to participate in the workshops, which they felt were 'real performances' instead of video shows and films.

\section{Understanding and learning about malaria using drama}

To assess if the project can be used to convey the three key messages of the project (to use insecticide-treated nets and repellents, to get early diagnosis and treatment, and to raise awareness about the risk of malaria in local forests), interviewers asked the villagers about the lessons that they had learnt from the drama.

When asked about the drama, villagers faced no difficulty recapitulating the storyline, which comprised two main characters, one of whom slept under a bednet while the other slept without protection. The latter contracted malaria and went to meet the VMW, who performed a blood test to confirm the malaria diagnosis. He was given a three-day malaria medication and later recovered. The respondents felt that the team gave simple and straightforward key messages which were easy to understand to the local community, including people who were illiterate.

Some villagers said that the drama would bring about behavioural changes in their daily lives. Compared with before the drama, solely relying on mosquito nets, they would now use mosquito repellents during the day. Men who go to the forest would bring mosquito nets with them and wear long-sleeved clothing.

\section{Entertainment value and engagement method preferences} The drama performance was described as funny and entertaining, and made learning and understanding about malaria much more interesting compared with the conventional health education methods. Villagers especially enjoyed watching children dressed as mosquitoes while singing songs about malaria. They were seen dancing away on the open ground in front of the stage. The catchy tunes meant villagers could easily join in the singing, and often were able to remember the messages in the songs.

Amongst the activities held during the evening (singing competitions, songs and a quiz on malaria, drama performance), drama was reported to be the favourite, followed by songs on malaria. Audience members used Facebook, which is very popular with Cambodians, to upload pictures and videos of the performances.

The provincial health department and local healthcare staff commented that health education without entertainment may not be appealing to the villagers. Combining arts and science led people to remember key messages better. Using drama to attract people in the village, and incorporate key messages about malaria achieved both entertainment and education purposes.

\section{Challenges to community engagement}

Reaching the forest goers and migrant population was a particular challenge. On each visit, forest workers typically spend one week to ten days in the forest; they make two trips per month, whereas migrants move in and out of the villages depending on planting and harvest seasons. For many forest workers who were unable to attend the event, their partners said that they would get their husbands to use repellents when they go into the forest in the future.

The village leader and local health staff raised the villagers' concerns regarding rumours that healthcare personnel came to the villages to collect their blood and sell it. Some respondents also described how other villagers believe in spiritual and psychic mediums to cure their illnesses. Some villagers reported limited understanding of the project aim, and this led to reservations about participation. Questions raised included, "who are [the drama team]?', 'where do they come from?' and 'what are they doing here?'.

".......because they believe in the superstitions like they believe in burning incense for the offering. They said they don't want to do blood test or to have vaccinations." (audience)

"And some people they said that oh...maybe take their blood for selling. Because they don't know. Because in Cambodia they sell blood."

(local health staff)

Social relationships in Cambodia embody a hierarchical pattern. The villagers' attitudes and participation appear to be heavily influenced by the village leaders and monks, who are respected members of the community. Establishing trust and good relationships with local village and spiritual leaders, and gaining their support implied subsequent participation from the villagers.

The VDAM organisers commented that the project which was conducted from June to September 2016 coincided with the 
rainy season in Cambodia. Roads that were already a bumpy ride for motorists were further battered due to the heavy downpour, making them inaccessible via small trucks used by the local drama team. The performance schedule often needed rearrangements because bridges connecting villages collapsed due to the flood.

\section{Future participation}

Many interviewees requested that the VDAM team organise the event again and said that they would participate in the future because very few events are organised in their villages. Some wanted their family members to participate in the event so that they would remember the key messages more effectively. The local health staff commented health education without properly engaging the community results in minimal impact.

\section{Sustainability}

The MORU team worked closely with the provincial health department and village leaders. Interviews with these key members suggested that villagers gained a better understanding of the purpose of malaria elimination projects after they conveyed these messages to the villagers. Some villagers said they were now more willing to do blood testing, which was conducted as part of malaria research conducted by MORU.

Interviewee: "For me, I really think this is very valuable for the community."

Interviewer: "Really, uncle? So it provides benefits for the community?"

Interviewee: "Yes, it really does. And recently people have involved in activities, for example: blood testing and so on."

(audience)

During the focus group discussion, youths felt that they learned how to perform in public and to express their thoughts. They further requested for materials related to ways of preventing malaria so that they could spread such awareness in schools. At the end of the project, video recordings and photos of the workshops and performances in the form of DVDs were distributed to all village leaders as souvenirs. All photos and videos were taken at public places and with formal written permission from the national and provincial authorities.

\section{Discussion}

Our results showed that the VDAM project was a feasible method to engage the rural communities and to convey the key malaria messages. Villagers said they learned more about malaria through the drama, enjoyed watching and participating in the performances and were keen to participate in future events. To our knowledge, the current paper is the first assessment of using drama to engage the community for malaria control and elimination.

\section{Drama within a community engagement strategy}

Community engagement is increasing recognized as integral to successful and ethical health-related research ${ }^{17}$. To maximize the efficiency of the community engagement programme, a combination of 'top-down' and 'bottom-up' approaches are needed ${ }^{18}$. Such a combination of approaches was taken to promote VDAM project. Taking 'top-down' approach, support was garnered from the provincial health department, village leaders and other respected members of the community which would then convince the local communities to participate. Taking a 'bottom-up' approach, local communities were encouraged to actively participate in the planning and execution of the 3-day event and to contribute stories and ideas to the drama performance, an approach the villagers claimed they have never experienced before.

Our community engagement project used traditional Cambodian drama to incorporate key messages about malaria prevention and elimination. A similar method was used in a study in Laos which utilized traditional folk songs known as 'lam' as an educational medium for preventing HIV/AIDS ${ }^{13}$. Based on interviews in the focus group discussions, the authors concluded that traditional folk songs could be used to motivate individual behavioural changes and to encourage community action for disease prevention. However, traditional songs were less enticing to the younger generations who preferred pop songs. Our engagement project used drama and various music genres which appealed to both the younger and older generations.

\section{Challenges to drama as community engagement}

Due to the timing of approvals, the project was conducted during the rainy season. Travelling from one village to another was considerably slower and everything took longer. Performance dates were often rescheduled due to the degraded road conditions. Frequent heavy downpours also made it more difficult for villagers to participate in the drama workshops and performance. Malaria incidence occurs throughout the year but most malaria cases are confined to the months during or directly after the rainy season; it would have been more appropriate to deliver the malaria messages before the rainy season begins. In a few villages with large population of over 1000 people, the villages consisted of several hamlets which were scattered. It was too far for villagers to walk to the event location, which resulted in lower participation rates in those villages.

Another challenge faced by the VDAM team was the time pressure. It was crucial to allocate enough time in each village without compromising the ability to convey the key malaria messages. However, with twenty villages to perform in, the length of time spent in each village was limited to only three days. As a result, we were unable to reach a large number of young men who were mainly forest workers who spend a significant amount of time in the forests, and the mobile and migrant population who were not in the villages.

\section{Limitations}

Since this engagement project had time and budget limitations, a longitudinal evaluation was not feasible. Furthermore, it was not possible to differentiate the VDAM project from other engagement and educational projects provided by the provincial health department, schools and VMWs. Since there was no before and after comparison made, it was not possible to determine the extent of changes in knowledge of malaria amongst villagers. The ultimate indicator of success is the elimination of malaria in these villages, which would be attributable to many factors. 
Our sample size was small as we were limited by practicalities: chiefly the interviewers could not attend all of the remote villages where the drama took place. The performances tended to end quite late at night and villagers had to go home immediately after the event ended to wake up early the next day. Many people also appeared to be shy and somewhat reluctant to be interviewed.

\section{Conclusions}

We conclude that although there were many challenges, village drama and its associated activities such as competitions and workshops is feasible as a community engagement strategy. Audience members recalled the plot of the performance and the malariarelated messages, indicating that the key messages were clear and concrete. Villagers perceived drama as entertaining and as the preferred choice of community engagement activity. Using drama is a promising way to engage communities and could be considered as part of the community engagement for malaria elimination.

\section{Abbreviations}

CNM: Cambodian National Centre for Parasitology, Entomology and Malaria Control; MEAF: Malaria Elimination Action Framework; MORU: Mahidol-Oxford Tropical Medicine Research Unit; VDAM: Village Drama Against Malaria; VMW: village malaria worker.

\section{Ethical statement}

The study was approved by the Oxford Tropical Research Ethics Committee (OXTREC; 1015-13), National Ethics Committee for Health Research Cambodia (18 ${ }^{\text {th }}$ Feb 2016 NECHR 0051), and registered on clinicaltrials.gov (NCT01872702). Verbal informed consent was obtained from all participants prior to commencing the interviews and questionnaires. Verbal consent for this study was approved by OXTREC in accordance with their guidelines on consent (https://www.admin.ox.ac.uk/curec/resources/informedconsent/) as well as the local ethics committee. Approvals for the VDAM project, use of social media as well as filming and photography for all public events were obtained from the national and provincial authorities prior to the start of the project.

\section{Data availability}

Due to ethical and security considerations, the data that supports the findings in this study can be accessed only through the Data Access Committee at Mahidol Oxford Tropical Medicine Research Unit (MORU). The data sharing policy can be found here: http:// www.tropmedres.ac/data-sharing. The application form for datasets under the custodianship of MORU Tropical Network can be found as a Supplementary File.

\section{Competing interests}

The authors declare that they have no competing interests.

\section{Grant information}

This work was supported by the Wellcome Trust [096527 and 106698].

The funders had no role in study design, data collection and analysis, decision to publish, or preparation of the manuscript.

\section{Acknowledgements}

This project was conducted by the Mahidol-Oxford Tropical Medicine Research Unit (MORU) in collaboration with the Battambang Provincial Health Department. MORU works in Cambodia in partnership with the National Center for Parasitology Entomology and Malaria Control.

We thank the communities, village leaders, school directors, health centres, and local authorities in Battambang that participated in this project. We also thank Nicholas Day (MORU), Kayna Kol (MORU), Chhouen Heng (MORU), Kem Sovann (MORU), Coco Snethlage (MORU), Mark Droogleever (MORU), Pachararit Wismol (MORU), and Abby Taylor (Wellcome Trust, UK). Photography and videography by Nicky Almasy at N/A Productions. Permission has been obtained by the named individuals to be acknowledged in the manuscript.

\section{Supplementary material}

Supplementary File 1: The application form for datasets supporting this research, under the custodianship of MORU Tropical Network.

Click here to access the data.

1. Lwin KM, Imwong M, Suangkanarat $\mathrm{P}$, et al.: Elimination of Plasmodium falciparum in an area of multi-drug resistance. Malar J. 2015; 14: 319. PubMed Abstract | Publisher Full Text | Free Full Text

2. Tripura R, Peto TJ, Chalk J, et al.: Persistent Plasmodium falciparum and Plasmodium vivax infections in a western Cambodian population: implications for prevention, treatment and elimination strategies. Malar J. 2016; 15(1): 181. PubMed Abstract | Publisher Full Text | Free Full Text
3. Maude RJ, Nguon C, Ly P, et al:: Spatial and temporal epidemiology of clinical malaria in Cambodia 2004-2013. Malar J. 2014; 13: 385. PubMed Abstract | Publisher Full Text | Free Full Text

4. Noedl H, Se Y, Schaecher K, et al.: Evidence of Artemisinin-Resistant Malaria in Western Cambodia. N Engl J Med. 2008; 359(24): 2619-2620. PubMed Abstract | Publisher Full Text

5. Phyo AP, Nkhoma S, Stepniewska K, et al.: Emergence of artemisinin-resistant 
malaria on the western border of Thailand: a longitudinal study. Lancet. 2012; 379(9830): 1960-6

PubMed Abstract | Publisher Full Text | Free Full Text

6. Ashley EA, Dhorda M, Fairhurst RM, et al.: Spread of Artemisinin Resistance in Plasmodium falciparum Malaria. N Engl J Med. 2014; 371(5): 411-423. PubMed Abstract | Publisher Full Text | Free Full Text

7. Tun KM, Imwong M, Lwin KM, et al: Spread of artemisinin-resistant Plasmodium falciparum in Myanmar: a cross-sectional survey of the K13 molecular marker. Lancet Infect Dis. 2015; 15(4): 415-21.

PubMed Abstract | Publisher Full Text | Free Full Text

8. Cambodia Malaria Elimination Action Framework (2016-2020). 2016. Reference Source

9. Canavati SE, Lawpoolsri S, Quintero CE, et al:: Village malaria worker performance key to the elimination of artemisinin-resistant malaria: a Western Cambodia health system assessment. Malar J. 2016; 15(1): 282. PubMed Abstract | Publisher Full Text | Free Full Text

10. Guyant P, Canavati SE, Chea N, et al.: Malaria and the mobile and migrant population in Cambodia: a population movement framework to inform strategies for malaria control and elimination. Malar J. 2015; 14(1): 252. PubMed Abstract | Publisher Full Text | Free Full Text

11. Wangroongsarb $P$, Satimai W, Khamsiriwatchara A, et al.: Respondent-driven sampling on the Thailand-Cambodia border. II. Knowledge, perception, practice and treatment-seeking behaviour of migrants in malaria endemic zones. Malar J. 2011; 10(1): 117.

PubMed Abstract | Publisher Full Text | Free Full Text

12. National Institute of Statistics, Directorate General for Health, ICF International:
Cambodia Demographic and Health Survey 2014. National Institute of Statistics, Directorate General for Health, and ICF International: Phnom Penh, Cambodia, and Rockville, Maryland, USA. 2015

Reference Source

13. Yoshida I, Kobayashi T, Sapkota S, et al.: Evaluating educational media using traditional folk songs ('lam') in Laos: a health message combined with oral tradition. Health Promot Int. 2012; 27(1): 52-62. PubMed Abstract | Publisher Full Text

14. Kroeger A, Meyer R, Mancheno M, et al:: Health education for community-based malaria control: an intervention study in Ecuador, Colombia and Nicaragua. Trop Med Int Health. 1996; 1(6): 836-46. PubMed Abstract | Publisher Full Tex

15. Mahasarinand P: Stop popping pills. 2016 Reference Source

16. Lim R, Peto TJ, Tripura R, et al:: Village Drama Against Malaria. Lancet. 2016; 388(10063): 2990

PubMed Abstract | Publisher Full Text

17. Tindana PO, Singh JA, Tracy CS, et al:: Grand challenges in global health: community engagement in research in developing countries. PLOS Med. 2007; 4(9): e273.

PubMed Abstract | Publisher Full Text | Free Full Text

18. Atkinson JA, Vallely A, Fitzgerald L, et al:: The architecture and effect of participation: a systematic review of community participation for communicable disease control and elimination. Implications for malaria elimination. Malar J. 2011; 10: 225.

PubMed Abstract | Publisher Full Text | Free Full Text 


\title{
Open Peer Review
}

\section{Current Peer Review Status: ? $\checkmark$ ?}

Version 1

Reviewer Report 13 October 2017

https://doi.org/10.21956/wellcomeopenres.13638.r26533

(c) 2017 Davies A. This is an open access peer review report distributed under the terms of the Creative Commons Attribution License, which permits unrestricted use, distribution, and reproduction in any medium, provided the original work is properly cited.

\author{
Alun Davies \\ ${ }^{1}$ Kenya Medical Research Institute-Wellcome Trust Research Programme, Kilifi, Kenya \\ 2 The Centre for Tropical Medicine, University of Oxford, Oxford, UK
}

Overall, I feel that the novel approach described in this project is worthy of disseminating to wider engagement audiences. The study is described in a fairly clear way; however, aspects could be improved on to strengthen the article.

Firstly, I would encourage the authors to clearly reference the Facebook and YouTube links explicitly with hyperlinks within the document if this is possible. The footage and images within these links clearly convey: the nature of the engagement; the participants and audiences involved in the activities; some of the challenges the authors and implementers encountered; and the sheer enjoyment of the participants in taking part in the activities. These are incredibly beautiful and striking images which bring the article alive and so are worth making the most of (assuming of course that the participants are happy for their images to be shared).

There is a risk that readers may interpret the project as using a 'deficit model' of engagement, where educated researchers enter 'illiterate' communities to fill the knowledge gaps. Though the main aim of the activities described is explicitly stated as addressing health knowledge gaps related to Malaria control, I feel that more of an emphasis could be made of the close collaboration between researchers and community members required in implementing this project, drawing on existing local talent and knowledge, towards addressing goals of engagement/health promotion. This collaboration was especially evident in the videos. In relation to this, if the data-set included evidence of a strengthening relationship, mutual-understanding or trust between researchers and participants, then this would be worth including.

There is some ambiguity about the overall aim of the engagement/research. The abstract states that the purpose of the project is to assess the feasibility of a drama project as a community engagement strategy. The description however, lacks an ethical argument as to why the authors selected health-promotion activities as a vehicle for engaging communities. Playing devil's advocate, it could be argued that health promoting activities such as "using insecticide-treated 
bednets and repellents, etc." rather than being the role of health researchers, is the work of the the Cambodian National Centre for Parasitology, Entomology and Malaria Control (CNM), through their Malaria Elimination Action Framework (MEAF) 2016-2020. Since the discussion presents a case that this is an engagement project 'integral to successful and ethical health-related research,' more clarity is needed in arguing why conducting health-promotion activities addresses ethical goals of community engagement. For example, did the implementers feel that they were well placed to conduct these activities, given their knowledge of malaria, to conduct health promotion? Was it a form of addressing 'justice' and 'beneficence' in research through offering community members means of improving their health? Was the purpose of the engagement to strengthen community members understanding of Malaria control, in order to complement informed consent for a specific MORU study (addressing 'respect for persons')? Or was it a means of strengthening relationships between research host communities and researchers (there is some evidence of this - leaders felt that participation offered an opportunity to learn about the work of MORU)? ... or was it a combination of all of these? I feel that using health-promotion as a means of engagement is entirely justifiable (see for example Participants in the CE and Consent Workshop (2013) ${ }^{1}$ or (Nakibinge et al., 2009²), but I think the ambiguity could be cleared with a short description/justification of why they are using it.

In relation to the above paragraph it would be helpful to provide a clearer description of the Malaria Elimination Action Framework (MEAF) 2016-2020. Is this a guideline document, or a group of government interventions, or both? Is the Battambang Provincial Health Department responsible for implementing this framework? If so, what are they already doing on the ground? Does MORU have a "Malaria elimination', or related study which this engagement project is part of, or is the project a stand-alone?

I agree with other referees with regards to the following points

Requiring reference to the value of working with participatory visual methods as a community engagement approach in public health and health research The relatively small sample size, but that this is acknowledged as a limitation

The overlaps with regards to the data presented within the findings themes and how these could be streamlined

In addition to the above points, I would have liked to have seen more participant quotes to highlight some of the qualitative findings, for example, in the following areas: a) the drama bringing about reported behaviour change; b) a quote from the children's song; c) a quote highlighting that drama was the preferred activity; d) evidence of establishing trust by community leaders translating to subsequent participation; and e) evidence of a desire for further participation.

This article provides a description of the creative use of a culturally appropriate method to engage communities with health and health research. As such it is worthy of being indexed.

\section{References}

1. Participants in the Community Engagement and Consent Workshop, Kilifi, Kenya, March 2011: Consent and community engagement in diverse research contexts.J Empir Res Hum Res Ethics. 2013; 8 (4): 1-18 PubMed Abstract | Publisher Full Text

2. Nakibinge S, Maher D, Katende J, Kamali A, et al.: Community engagement in health research: two decades of experience from a research project on HIV in rural Uganda.Trop Med Int Health. 2009; 14 (2): 190-5 PubMed Abstract | Publisher Full Text 
Is the work clearly and accurately presented and does it cite the current literature? Partly

Is the study design appropriate and is the work technically sound?

Yes

Are sufficient details of methods and analysis provided to allow replication by others? Partly

If applicable, is the statistical analysis and its interpretation appropriate? Not applicable

Are all the source data underlying the results available to ensure full reproducibility? No source data required

Are the conclusions drawn adequately supported by the results?

Yes

Competing Interests: No competing interests were disclosed.

Reviewer Expertise: Public/community engagement with health research

I confirm that I have read this submission and believe that I have an appropriate level of expertise to confirm that it is of an acceptable scientific standard, however I have significant reservations, as outlined above.

Author Response 13 May 2018

Renly Lim, Mahidol University, Bangkok, Thailand

Dear Dr Davies,

We would like to thank you for taking the time to review our paper and for the helpful suggestions. Below is our point-by-point response:

Comment 1: Firstly, I would encourage the authors to clearly reference the Facebook and YouTube links explicitly with hyperlinks within the document if this is possible. The footage and images within these links clearly convey: the nature of the engagement; the participants and audiences involved in the activities; some of the challenges the authors and implementers encountered; and the sheer enjoyment of the participants in taking part in the activities. These are incredibly beautiful and striking images which bring the article alive and so are worth making the most of (assuming of course that the participants are happy for their images to be shared).

Response 1: We agree with the reviewer's suggestion and have added the Facebook and YouTube links in the methods, 'The VDAM community engagement project' section. We obtained formal written permission from the national and provincial authorities as well as verbal consent prior to taking any images and video footages, and have obtained permission to share these materials. 
Comment 2: There is a risk that readers may interpret the project as using a 'deficit model' of engagement, where educated researchers enter 'illiterate' communities to fill the knowledge gaps. Though the main aim of the activities described is explicitly stated as addressing health knowledge gaps related to Malaria control, I feel that more of an emphasis could be made of the close collaboration between researchers and community members required in implementing this project, drawing on existing local talent and knowledge, towards addressing goals of engagement/health promotion. This collaboration was especially evident in the videos. In relation to this, if the data-set included evidence of a strengthening relationship, mutual-understanding or trust between researchers and participants, then this would be worth including.

Response 2: Agree with the reviewer's comments that we should elaborate on the close relationship between our staff and the local community. We have added the following in the methods and results section:

-Methods

Planning and involvement of local people

MORU has a long standing relationship with Cambodian health authorities. Since 2013, MORU has conducted malaria prevalence studies in villages in western Cambodia [18], and since 2015, targeted malaria elimination studies involving mass drug administration has been on-going in villages in Western Cambodia. All projects involve local stakeholders at the national, provincial and village level. In the VDAM project, local leaders and community are involved in its planning and implementation.

-Results

Our project which incorporated use of a community-directed approach while maintaining a close collaboration between MORU staffs and local leaders contributed to the success of this project.

"........for the program to run smoothly depends on the local people and stakeholders joining to help each other like all of you come to help my community. ....... Unless the people who are responsible in the village cooperate and work together the work will not run smoothly." (audience)

Comment 3: There is some ambiguity about the overall aim of the engagement/research. The abstract states that the purpose of the project is to assess the feasibility of a drama project as a community engagement strategy. The description however, lacks an ethical argument as to why the authors selected health-promotion activities as a vehicle for engaging communities. Playing devil's advocate, it could be argued that health promoting activities such as "using insecticide-treated bednets and repellents, etc." rather than being the role of health researchers, is the work of the the Cambodian National Centre for Parasitology, Entomology and Malaria Control (CNM), through their Malaria Elimination Action Framework (MEAF) 2016-2020. Since the discussion presents a case that this is an engagement project 'integral to successful and ethical health-related research,' more clarity is needed in arguing why conducting health-promotion activities addresses ethical goals of community engagement. For example, did the implementers feel that they were well placed to conduct these activities, given their knowledge of malaria, to conduct health promotion? Was it a form of addressing 'justice' and 'beneficence' in research through offering community members means of improving their health? Was the purpose of the 
engagement to strengthen community members understanding of Malaria control, in order to complement informed consent for a specific MORU study (addressing 'respect for persons')? Or was it a means of strengthening relationships between research host communities and researchers (there is some evidence of this - leaders felt that participation offered an opportunity to learn about the work of MORU)? ... or was it a combination of all of these? I feel that using health-promotion as a means of engagement is entirely justifiable (see for example Participants in the CE and Consent Workshop (2013) ${ }^{1}$ or (Nakibinge et al., $2009^{2}$ ), but I think the ambiguity could be cleared with a short description/justification of why they are using it.

Response 3:

We agree that the aim has not been stated clearly. We have added the following in the introduction and methods section:

-Introduction

The aim of this qualitative study is to assess the feasibility of a drama project as a community engagement strategy to raise awareness of a health problem in the community and improve the community's understanding of the disease in question, in this case malaria.

-Methods

The VDAM project was conducted alongside an on-going targeted malaria elimination study in six villages in Western Cambodia [17]. Our ethical justification is that community engagement has the potential to strengthen the consent process by increasing community understanding about malaria, which in turn aids understanding of a malaria study by prospective research participants.

Comment 4: In relation to the above paragraph it would be helpful to provide a clearer description of the Malaria Elimination Action Framework (MEAF) 2016-2020. Is this a guideline document, or a group of government interventions, or both? Is the Battambang Provincial Health Department responsible for implementing this framework? If so, what are they already doing on the ground? Does MORU have a "Malaria elimination', or related study which this engagement project is part of, or is the project a stand-alone?

Response 4: The Malaria Elimination Action Framework (MEAF) 2016-2020 is a national guideline delineating five strategic plans which would be implemented by 2020 in the hope of eliminating malaria in Cambodia. The framework is currently being implemented nationally by the Cambodian National Centre for Parasitology, Entomology and Malaria Control (CNM) and all implementing partners including the Battambang Provincial Health Department.

The community engagement project described in our paper was conducted alongside an on-going targeted malaria elimination study providing mass drug administration in six villages in Western Cambodia. We have clarified this in the methods section.

Comment 5: I agree with other referees with regards to the following points: Requiring reference to the value of working with participatory visual methods as a community engagement approach in public health and health research The relatively small sample size, but that this is acknowledged as a limitation The overlaps with regards to the data presented within the findings themes and how these could be streamlined 
Response 5:

We agree with the reviewer's suggestions. We have added two references discussing the value of participatory visual methods as a community engagement in the discussion section.

-Discussion

Our community engagement project used traditional Cambodian drama, a visual method of engagement, to incorporate key messages about malaria prevention and elimination. Participatory visual methods as a community engagement strategy can increase participant engagement and communication, allow participants to share their stories, opinions and experiences, and foster relationships between researchers and the participants [21,22]. With regards to the small sample size, this was mainly due to time constraint and language barrier. We were only able to arrange a limited number of short visits from MORU in Thailand where members of our evaluation group were working at, to the remote villages which were 10 to 12 hours away on road. In addition, having only one local translator who also held other responsibilities within the project, we could only conduct a few interviews during each visit. Hiring a translator from other places was not an option because we needed someone who has established rapport with the locals, in order to gain trust and permission to conduct interviews.

We are aware that there are overlaps between the areas explored in our interview guides and the resulting themes. Given the small sample size, the data that we were able to extract were also limited. As a result, the responses did not vary. We have added this to our study limitation.

Comment 6: In addition to the above points, I would have liked to have seen more participant quotes to highlight some of the qualitative findings, for example, in the following areas: a) the drama bringing about reported behaviour change; b) a quote from the children's song; c) a quote highlighting that drama was the preferred activity; d) evidence of establishing trust by community leaders translating to subsequent participation; and e) evidence of a desire for further participation.

Response 6:

We agree and have added more quotes from the interviews. The following quotes have been added in the results section:

i) on behavioural changes;

"........Now they (the husbands) use repellent. For the men when they go to the forest, they bring the mosquito net there and wear the long trousers and long shirt......." (audience)

ii) quote from the children's song;

"Everybody needs to know malaria; The mosquitoes they come biting; Stay inside mosquito nets, Everybody needs to know malaria; Prevent mosquitoes from hunting; Stay alive, do not miss the mosquito net." 
iii) a quote highlighting that drama was the preferred activity;

"Actually I liked most of the program, however one section that I am interested in was the drama because the indigenous people find it easy to understand. The short drama like people sleeping inside the mosquito net and sleeping outside the mosquito net (referring to the drama plot)."

(audience)

d) evidence of establishing trust by community leaders translating to subsequent participation;

"They followed the head of the indigenous community because normally the person who is the head of the indigenous people has influence and the indigenous people listen to the head."

(audience)

e) evidence of a desire for further participation.

"I think it would be great for you to come many times because sometimes when we just use our words to teach people it doesn't really directly impact them."

(audience)

"If possible, my suggestion is to have this event every year because if we go for a long time without doing the events then the community could forget it but if we do it every year or two times a year then it will help to remind the community about using the mosquito nets whenever they sleep at home or out in the forest or farming. Then they can apply the message because they have seen the drama every year."

(audience)

Competing Interests: No competing interests were disclosed.

Reviewer Report 06 October 2017

https://doi.org/10.21956/wellcomeopenres.13638.r26534

(c) 2017 Chambers M. This is an open access peer review report distributed under the terms of the Creative Commons Attribution License, which permits unrestricted use, distribution, and reproduction in any medium, provided the original work is properly cited.

\section{Mary Chambers}

Oxford University Clinical Research Unit (OUCRU), Ho Chi Minh City, Vietnam

It is timely to have a publication describing the strengths and weaknesses of community engagement activities. Pressure from funders and increasing researcher interest in engagement means that more biomedical trials and research studies have a community engagement 
component. However, publications evaluating their effectiveness are scarce.

The authors clearly state the reasons for and the methods of engagement. The genre of engagement seems appropriate for the population served, as backed by the evaluation. The data collection is described clearly, although I would like the authors to clarify the timeframe between the activities and the interviews/focus group. This is relevant if they are assessing recall of the theatre script content and attributing the engaging methods of health promotion for people's ability to remember the key health messages.

The number of participants is small and ideally they would have interviewed more villagers, and at different time points. The authors acknowledge this as a limitation to the study.

The discussion is clear and conclusions appropriate. However, I would question the overall conclusion that village drama could be considered as part of CE for malaria elimination without some discussion as to whether these activities are prohibitively costly for local health systems to conduct. The question of sustainability as an imbedded CE/public health activity is not addressed. Perhaps the conclusion that they may be effective as part of an externally funded research engagement strategy would be more appropriate.

These minor limitations do not prevent this from being a well written and useful contribution to the literature about community engagement in a biomedical research setting.

Is the work clearly and accurately presented and does it cite the current literature? Yes

Is the study design appropriate and is the work technically sound? Yes

Are sufficient details of methods and analysis provided to allow replication by others? Yes

If applicable, is the statistical analysis and its interpretation appropriate? Not applicable

Are all the source data underlying the results available to ensure full reproducibility? Yes

Are the conclusions drawn adequately supported by the results? Yes

Competing Interests: No competing interests were disclosed.

I confirm that I have read this submission and believe that I have an appropriate level of expertise to confirm that it is of an acceptable scientific standard. 
https://doi.org/10.21956/wellcomeopenres.13638.r26538

(C) 2017 Black G. This is an open access peer review report distributed under the terms of the Creative Commons Attribution License, which permits unrestricted use, distribution, and reproduction in any medium, provided the original work is properly cited.

\section{Gillian F. Black (iD)}

Sustainable Livelihoods Foundation, Cape Town, South Africa

\section{Is the work clearly and accurately presented?}

For the most part, the work is clearly and accurately presented, but important clarifications are required at certain points.

It is emphasized throughout that drama is the key engagement strategy being evaluated. However, the VDAM community engagement approach (at each site) comprised of a 3-day workshop including art, music, village concerts and competitions, with a (participatory) drama performance taking place on the final evening. As far as I can understand, drama was not used in isolation in any of the participant villages. So using the term 'drama project' is questionable. The authors could perhaps consider another term that better reflects the multi-pronged nature of the community engagement approach taken.

The authors explain that the project took place between June and September 2016, and that the interviews and focus group discussions were conducted in July of that year. Details are provided about the groups who were included in these processes, and the number of respondents. Were all of the respondents from the same village? (i.e. are all responses based on a single 3-day workshop event?). It is important to know this as it will indicate which of the study areas are represented in the results and conclusions. (At several points in the paper, the authors refer to 'the' event or 'the' performance, which indicates that the results are indeed based on the implementation of a single workshop activity. Please do clarify if this was the case).

It is explained that the project also included modern technologies such as drones to film the villages and social media to share photos and videos across the province. These elements of the engagement process do not inform the research findings described in the article. I was left wondering why this information was included in the paper, what the main purpose of this province wide dissemination was, and what the ethical implications of these disseminations approaches were.

The average rate of event participation is calculated to be $66 \%$ across all the villages, and this statistic is highlighted in the paper abstract. The authors explain that a single 3-day workshop was held for each village, that there is appreciable variation in the size of the villages, and that the majority of villagers commute on foot, making it potentially difficult for residents of the largest villages to attend the drama events (due to walking distance). The suggestion that walking distance may explain lower participation rates in larger villages could be substantiated by a formal but simple analysis of population size versus percent attendance. A comment on the feasibility/practicality/value of implementing more than one workshop in the larger villages would be helpful, too.

I felt that certain parts of the results section (e.g. page 6 'Combining arts and science...' and 'Social relationships in Cambodia...') would be more appropriately placed in the discussion. 


\section{Current literature}

In the discussion, the authors mention that - to their knowledge - 'the current paper is the first assessment of using drama to engage ' the community' for malaria control and elimination'. M Frishkopf and his colleagues have recently published research showing that a performing arts public health intervention in northern Ghana was effective to convey key messages about malaria transmission to local audiences (Frishkopf M. et al, 2016¹)

Additional reference to growing international recognition of both the value and ethics of community engagement in health-related research could be included. (King KF et al., 2014². Wallerstein and Duran, $2010^{3}$ ).

The key community engagement intervention strategy that is discussed in this paper is participatory drama. Drama is a visual method of engagement. Some reference to the value of working with participatory visual methods as a community engagement approach in public health and health research would add an important element to the current article (Mitchell and Sommer, $2016^{4}$ )

\section{Are sufficient details of methods and analysis provided to allow replication by others?} On page 5, the authors explain that their sampling method was purposive and limited by practicalities, but. To enable replicability, it would have been helpful to be given a brief description of the process through which interview respondents and focus group members were selected.

The authors also explain that semi-structured interviews were done with various groups, including five professional actors one village malaria worker. The results section describes thematic key responses from different participant groups - especially the villagers - but there is no mention of responses from the actors or the VMWs. A complete understanding of the feasibility of the engagement strategy will only be gained through including the perspectives of all research respondents in the analysis.

The description of the drama workshops and performances indicates that the drama was partly developed before the village engagement activities began, and then further developed during the workshop. This further development included participation from teenagers and young people, at each site, by the incorporation of their personal stories and experiences. This process of drama development is a very important part of the methodology and approach to community engagement. I would suggest that a bit more detail is provided here as to the steps taken, for the purposes of replicability by others in the field. In the interest of the word count, this could perhaps be written in detail as supplementary material.

The section describing the main storyline for the play is currently included in the results section (page 6). It does not describe the results of the data analysis, and would be more appropriately placed in the methods section. However, the storyline description is not necessary to the understanding of the project and could be left out entirely.

\section{Are the conclusions drawn adequately and supported by the results?}

Seven themes were surfaced through analysis of the data generated by the interviews and focus group discussions. There is a large overlap between the areas explored in the interview guides and the resulting themes. This is not entirely surprising, given the small sample size in each 
respondent group, but it is worth noting as a study limitation.

The groups that participated in the interviews/focus group discussions, and the number of respondents in each of these groups, is described on page 5. For example, we know that there was 1 local health staff respondent and 1 village leader respondents. However, at several points in the results sections, the writing indicates that there were multiple respondents in these groups. ('Staff from the local health authority felt...', and 'Village leaders were interested because...'. The text needs to more accurately reflect the singular nature of these responses, and of the other interviewed groups that contained a single respondent.

I wonder if sustainability is a relevant theme to be discussed this paper, based on the results of the data analysis that are described. The actual responses cited in this section refer to better understanding about malaria elimination projects that were gained through the engagement approach, which would seem to fit under theme 3 (understanding and learning about malaria using drama). Also, increased willingness of villagers to do blood testing does not speak to the sustainability of the engagement approach that is being evaluated, but rather to its impact. I would suggest revisiting this section and thinking about which parts are results that could be included under other themes, and which parts could be moved to the methods or discussion sections.

The conclusions that are drawn are based on both the rates of participation in each village (averaging out at 66\%) and the results from interviews and focus group sessions. In the section on data collection, the authors do acknowledge that their sampling was limited by practicalities, but the small sample size of each respondent group is a key limitation and this needs to be noted in the conclusion section.

\section{Additional Comments}

In the results section of the abstract, it is indicated that 'The event saw a very positive response...' Again this indicates that - even although the project included community engagement activities in 20 villages - the article is based on a single engagement event. If this is the case, readers should be made aware of this in the abstract.

In the conclusion of the abstract, it is stated that 'the drama project was feasible in promoting awareness and understanding of malaria prevention and control'. This statement could be qualified by adding 'in this context' (i.e. rural settings in S.E. Asia). I would make the same suggestion for the final concluding statement in the paper.

In the discussion, it would have been interesting to hear some of the authors reflections on the ethical considerations of using this specific approach to community engagement, having gained this important experience. For example, as far as I can see, approvals for the use of social media, filming and photography were only gained from the provincial authorities. Is this level of approval sufficient? If so, why is this considered to be the case? Did the project process foster expectations about the elimination of malaria in the district? If so, how were such expectations managed by the MORU team?

In the discussion, a sentence or two indicating the authors learning from using a professional, touring drama team as the lead performers in a participatory process would also have valuable. 
Page 3. The explanation of literacy rates needs to be clarified For example : The 2014 census indicated literacy rates to be $93 \%$ and $77 \%$ in urban and rural areas, respectively.

On page 5, the authors explain that approval for the main script, storyline and key messages was sought from provincial health authorities. Was approval for these things also sought, at any stage, from villagers, VMW or local health staff?

The authors explain that the average number of attendees at each village performance was 430 . This is a large audience size for a community drama event. Were there any implications of this, for example background noise levels, or children running around? Were microphones/speakers used in this process? I wonder if this element of the drama engagement was explored through the interviews or focus groups. These are also important methodological details for the purposes of replicability.

\section{Minor comments}

In five cases, the spelling/formatting of the village names differs between the map (Figure 1) and Table 1.

The ethical statement on page 5 is duplicated on page 8.

This interesting research article provides important insights into the possibilities and challenges for multi-pronged, creative community engagement strategies to contribute to malaria elimination in rural South East Asia. With a little more reference to directly resonant publications, greater attention to grammar in some places, the repositioning of certain content, and the inclusion of ethical reflection, it will make an excellent and needed contribution to the community engagement in global health literature.

\section{References}

1. Frishkopf M, Hamze H, Alhassan M, Zukpeni I, et al.: Performing arts as a social technology for community health promotion in northern Ghana. Family Medicine and Community Health. 2016; 4 (1): 22-36 Publisher Full Text

2. King KF, Kolopack P, Merritt MW, Lavery JV: Community engagement and the human infrastructure of global health research.BMC Med Ethics. 2014; 15: 84 PubMed Abstract | Publisher Full Text

3. Wallerstein N, Duran B: Community-based participatory research contributions to intervention research: the intersection of science and practice to improve health equity.Am J Public Health. 2010; 100 Suppl 1: S40-6 PubMed Abstract | Publisher Full Text

4. Mitchell CM, Sommer M: Participatory visual methodologies in global public health.Glob Public Health. 11 (5-6): 521-7 PubMed Abstract | Publisher Full Text

Is the work clearly and accurately presented and does it cite the current literature? Partly

Is the study design appropriate and is the work technically sound? Partly

Are sufficient details of methods and analysis provided to allow replication by others? 


\section{Partly}

If applicable, is the statistical analysis and its interpretation appropriate?

Not applicable

Are all the source data underlying the results available to ensure full reproducibility?

No source data required

Are the conclusions drawn adequately supported by the results?

Partly

Competing Interests: No competing interests were disclosed.

Reviewer Expertise: Participatory visual methods for community engagement in public health and health science research

I confirm that I have read this submission and believe that I have an appropriate level of expertise to confirm that it is of an acceptable scientific standard, however I have significant reservations, as outlined above. 